\title{
O Centro de Campinas: habitação e ocupação do território 2000-2015
}

The Campinas Downtown: Housing and urban land occupation 2000-2015

El centro de Campinas: la vivenda y la ocupación del território 2000-2015

\author{
Viviana Pereira Gonçalves \\ Mestranda, UNICAMP, Brasil \\ vivianapgoncalves@yahoo.com.br
}

Silvia A. Mikami G. Pina Professora Doutora, UNICAMP, Brasil smikami@fec.unicamp.br 


\section{RESUMO}

As dinâmicas dos centros urbanos relacionadas ao despovoamento e degradação, faces do mesmo processo que levou à expansão das periferias urbanas, apresentam forte impacto na questão da habitação nos bairros centrais das grandes cidades brasileiras. Tal processo tem se caracterizado pela gentrificação na medida que a revitalização de espaços urbanos provoca a supervalorização desses espaços e a expulsão de população de baixa renda. Este trabalho caracteriza a ocupação habitacional contemporânea do centro urbano de Campinas de 2000 a 2015, a partir da análise da produção recente de habitação coletiva nos bairros centrais e sua caracterização populacional. Para tanto, apresenta-se um estudo de caso dos empreendimentos habitacionais aprovados no período na área central de Campinas formada pelo centro histórico e pelos bairros Guanabara, Cambuí e Bosque. Também se desenvolve um levantamento sobre o perfil da população residente nestes bairros no mesmo período. A análise combinada com as informações populacionais dos censos demográficos do período indica que, apesar do saldo migratório, o centro campineiro tem passado nos últimos anos por importantes transformações com incremento do crescimento da habitação verticalizada de alto padrão e respectiva substituição da população moradora por outra de maior poder aquisitivo, apontando para um cenário de enobrecimento social.

PALAVRAS-CHAVE: Área Central. Habitação Coletiva. Mudanças Demográficas.

\section{ABSTRACT}

The dynamics of urban centers related to the depopulation and degradation, faces of the same process that led to the urban suburbanization, have caused strong impact on the issue of housing in the central districts of Brazilian big cities. This process has been characterized by gentrification as the revitalization of urban areas leads to overvaluation of these spaces and the expulsion of the low-income population. This study characterizes the contemporary housing occupation of the urban center of Campinas between 2000 and 2015, based on the analysis of the recent production of multifamily housing in the central districts and their population characterization. Therefore, we present a case study about the projects approved in the period in Campinas Downtown formed by the historical center and the districts Guanabara, Cambuí and Bosque. A study about the resident population profile of central districts shows the transformation in the same period. The combined analysis with the population data of Brazilian Demographic Census for the period indicates that, despite the migratory balance, the central areas of Campinas have experienced important changes in recent years, with the increasing of the vertical housing growth for high-income people and the replacement of the resident population by another with greater purchasing power, pointing to a scene of gentrification.

KEYWORDS: Downtown Area. Multifamily Housing. Demographic Changes.

\section{RESUMEN}

Las dinámicas de los centros urbanos relacionadas a la despoblación y la degradación, caras del mismo proceso que condujo a la expansión de las periferia urbanas, tienen fuerte impacto en el tema de la vivienda en los distritos centrales de las grandes ciudades brasileñas. Este proceso se ha caracterizado por la gentrificación, proceso de revitalización de los espacios urbanos que provoca la sobrevaloración de estos espacios y la expulsión de la población de bajos ingresos. El objetivo de este estudio es caracterizar la ocupación habitacional contemporánea del centro urbano de Campinas entre 2000 y 2015, a partir de la análisis de la reciente producción de viviendas multifamiliares en los distritos centrales y la caracterización de su población. Por lo tanto, se hace un estudio de caso de proyectos de vivienda aprobados en el período en la region central de Campinas formado por el Centro Histórico y los barrios de Guanabara, Cambuí y Bosque. También desarrolla un estudio sobre el perfil de la población residente en estos distritos en el mismo período. El análisis combinado con los datos de población del Censo Demográfico brasileño para el período Indica que, a pesar del saldo migratorio, las áreas centrales de Campinas han experimentado cambios importantes en los últimos años, con el aumento del crecimiento de la vivienda vertical para las personas de altos ingresos y sustitución de la población residente por otra con mayor poder adquisitivo, apuntando a una escena de gentrificación.

PALABRAS CLAVE: Región Central, Vivienda Colectiva, Cambios demográficos. 


\section{INTRODUÇÃO}

A expansão irrestrita das periferias urbanas, impulsionada há décadas pelo desenvolvimento industrial, pela explosão demográfica e pelo modelo perverso de política urbana adotado na maioria das metrópoles brasileiras, vem modificando e agravando a segregação social, caracterizada pela dicotomia do centro rico versus periferia pobre. Outro fenômeno bastante comum é o deslocamento das classes de alta renda para condomínios horizontais em áreas distantes. Da mesma forma, a busca por novas áreas e centralidades tem impactado diretamente na ocupação dos bairros centrais, nos quais é comum ocorrer despovoamento e degradação. Dentre as dinâmicas ocorridas nos centros urbanos nas últimas décadas destacam-se tanto o processo de popularização quanto o de enobrecimento social ou gentrificação, ambos relativos a mudanças socioeconômicas provocadas pelos movimentos migratórios no território urbano e por politicas urbanas adotadas. A popularização caracterizase pela ocupação por população de renda mais baixa dos edifícios e espaços deixados para trás pelos antigos usuários. Já o enobrecimento social, comumente relacionado a projetos e políticas de renovação e revitalização urbana e às mudanças no uso do solo, diz respeito à atração de população de maior renda e grau de instrução para as áreas centrais, ocasionando a expulsão da população de renda mais baixa para outras áreas da cidade.

O centro da cidade de Campinas, inserida na macrometrópole de São Paulo, passou ao longo de sua história por importantes mudanças em seu espaço físico, na constituição de sua população e na ocupação habitacional do seu território. O constante processo de transformação se estende até os dias atuais, revelando um espaço bastante dinâmico. 0 adensamento construtivo do centro da cidade, impulsionado pelo Código de Obras de 1934 e pela implantação do Plano de Melhoramentos Urbanos de Prestes Maia em 1938 se deu principalmente pela intensificação da verticalização da área central. Os edifícios daquela época, embora predominantemente residenciais, apresentavam diversidade de tipologias de apartamentos e, na sua maioria com mistura de usos, sendo primeiros andares destinados ao uso comercial e de serviços (DEZAN, 2007). O Plano de Melhoramentos propôs o alargamento das principais vias do centro objetivando a modernização da cidade e a dispersão urbana. Após 1965, o centro da cidade passou a receber mais empreendimentos de caráter comercial e o adensamento residencial passou a ocorrer prioritariamente em outras áreas. Nos últimos anos, entretanto, mesmo com a transferência de alguns serviços da área central para pontos distantes na cidade, como os serviços judiciários e da educação superior, percebe-se a presença de um mercado forte de construção habitacional nos bairros centrais.

Este trabalho caracteriza a ocupação habitacional do centro urbano de Campinas, a partir de uma análise combinada da produção recente de habitações coletivas e das mudanças no perfil da população residente nos bairros centrais. O perímetro selecionado para o desenvolvimento da análise corresponde ao que a municipalidade reconhece como Área Central, ou seja, aquela formada pelo Centro Histórico e pelos bairros Guanabara, Cambuí e Bosque. Para a obtenção dos dados, foi realizada uma pesquisa documental junto à prefeitura municipal, que apontou a aprovação de cinquenta e três novos projetos de habitação coletiva dentro do perímetro de estudo, entre os anos de 2000 e 2015. A partir da análise dos processos consultados constatou-se que vários desses empreendimentos se dão por meio da anexação de lotes menores, indicando não apenas a transformação da tipologia e do adensamento habitacional, mas também de demanda por habitação de padrão mais elevado, indicando possível 
população de renda mais alta. Além disso, a comparação entre as características demográficas dos bairros centrais e das demais áreas do município permite diferenciar a região central dentro do contexto urbano, revelando sua importância e suas especificidades.

A pesquisa visa contribuir no sentido de possibilitar uma maior compreensão das dinâmicas de mudança de uso do solo e de produção habitacional em curso nos bairros centrais e seus efeitos, as quais parecem reiterar a hegemonia do setor privado na produção da cidade contemporânea, apoiado por políticas urbanas locais.

\section{OS CENTROS URBANOS CONTEMPORÂNEOS E AS DINÂMICAS DEMOGRÁFICAS}

Sobre a produção capitalista do espaço, Harvey (2006) coloca a relação de interdependência entre a urbanização e a economia, ressaltando que os modos de produção contemporâneos imprimem suas marcas sobre o território urbano, mas que também os processos de urbanização influenciam, na contramão, nos rumos do desenvolvimento social e econômico. Dessa forma, tanto o enfraquecimento do poder do Estado como regulador da produção do espaço urbano, quanto a sua associação indiscriminada com os interesses especulativos da iniciativa privada, dão condições para que a formação do tecido urbano e as modificações que ocorrem nas cidades sejam regidas pelas lógicas de mercado, transformando o solo urbano em uma das mercadorias mais rentáveis da atual fase do capitalismo.

A importância do centro da cidade está relacionada à formação da aglomeração, de modo que um não preceda o outro, mas surja através do mesmo processo, constituindo uma relação de interdependência (VILLAÇA, 1998). O centro é o ponto no território que minimiza os deslocamentos de toda a comunidade no acesso a espaços em comum. Como nem todos podem habitar o mesmo ponto no espaço ocorre a necessidade de afastamento, iniciando a disputa pelos locais mais próximos ao centro e que apresentam, portanto, maiores vantagens, indicando diferenciação nos valores relativos à localização. Conforme a cidade se expande, procura-se estender para outros locais a infraestrutura urbana, mas as características presentes no Centro não podem ser replicadas. É inegável, assim, a importância simbólica desse espaço enquanto local histórico e socialmente constituído de uma cidade, apresentando o maior nível de complexidade urbana e social. Ele é, também, o espaço mais acessível para o conjunto da sociedade, de acordo com as condições de mobilidade mais acessíveis. A importância da proximidade ao centro é relativizada conforme o desenvolvimento dos meios de transporte, pois esses alteram as condições de acessibilidade aos vários pontos da cidade. Mesmo assim, o controle sobre o espaço urbano permanece nas mãos das classes dominantes, as quais tem o poder de escolher seu local de moradia conforme suas condições e preferências particulares. Contudo, para a população de baixa renda resta como local de moradia, na maior parte das vezes, as periferias distantes e menos providas de infraestrutura ou de serviços urbanos.

A ideia contemporânea de centro urbano como centro de serviços tem criado uma heterogeneidade polarizada nas áreas centrais das grandes cidades. Os empregos oferecidos nesses locais costumam ser bastante diferenciados entre si: de um lado, as atividades informais ou empregos formais mal remunerados e do outro, empregos em setores de ponta com altos salários (HARVEY, 2006). Ainda sobre essa heterogeneidade pode-se dizer que o consumo e a atividade das classes populares, uma vez que o centro constitui um ponto de convergência para as mesmas, contribui para a manutenção do valor econômico da localização 
(VILLAÇA, 2012), ao mesmo tempo em que o ambiente físico é continuamente degradado, tornando mais fácil para o setor privado a aquisição de imóveis acessíveis. A tendência desse processo é a demolição das construções horizontais preexistentes e a anexação dos lotes, compondo terrenos maiores capazes de abrigar empreendimentos verticalizados. Os valores das unidades habitacionais produzidas refletem sua localização e conduzem às mudanças no perfil socioeconômico da população local e nas características do ambiente construído, criando possibilidade para que essa lógica se estenda, paulatinamente, por grande parte do território central, onde predomina o interesse do mercado imobiliário especialmente.

As mudanças e os efeitos socioeconômicos promovidas pelo tal processo são conhecidas por gentrificação (SMITH,2006), fenômeno também reconhecido sob o termo enobrecimento, uma vez que se refere à ideia de elevação do perfil social da população de um determinado lugar, tanto em termos econômicos quanto educacionais ou culturais, revelando seu caráter classista. $\mathrm{O}$ autor esclarece como o enobrecimento pode se tornar uma estratégia do mercado imobiliário e até do próprio governo local, ou da combinação de ambos os interesses, seguindo o caminho da privatização do setor habitacional e a maximização dos lucros advindos da comercialização da moradia. Embora o autor se utilize do caso de Nova York para explicar as lógicas que regem os processos de enobrecimento urbano, Smith (2006) deixa claro que o alcance do fenômeno é muito mais amplo, estendendo-se até os centros urbanos mais improváveis. Trata-se, portanto, de um processo bastante comum no desenvolvimento urbano contemporâneo em diversas partes do mundo, sendo diferenciado em cada caso por características locais. Além de representar a reconquista da cidade pelas classes mais altas a gentrificação “(...) produz também o espaço urbano falsamente democratizado, passível de ser "consumido" parcialmente por outras camadas sociais (BIDOU-ZACHARIEN, 2006, p. 34).

A verticalização construtiva está, por sua vez, associada ao preço da terra urbana, ou seja, quanto mais valorizada, maior tende a ser a verticalização e, geralmente, é um dos indicativos físico-espaciais do processo de enobrecimento de um local. A verticalização no Brasil era visualizada nas primeiras décadas do século XX como símbolo de progresso e modernidade, propiciada pelo advento do elevador. Primeiramente, as edificações verticalizadas eram ligadas ao uso do setor terciário e, pouco a pouco, tornou-se predominantemente residencial no contexto de algumas cidades, como São Paulo. A política de limitação do coeficiente de aproveitamento e a instituição de um tamanho mínimo para a unidade habitacional acabou direcionando o atendimento principalmente da demanda das classes de renda média e alta (SOMEKH, 1997). Essa lógica ainda hoje perdura nas áreas mais valorizadas das grandes cidades, onde o alto custo da terra leva o mercado a fazer investimentos muito lucrativos em áreas já providas de infraestrutura, por vezes levando o poder público a substituí-la por outra mais avançada ou de maior alcance, em detrimento das periferias, cuja infraestrutura básica sequer chegou. Estas ações acirram ainda mais as diferenças de valor urbano e de acesso à cidade no seu pleno potencial.

\section{O CENTRO DE CAMPINAS: MUTAÇÕES NO USO HABITACIONAL}

Assim como ocorreu em São Paulo, Campinas também recebeu influência das ideias modernizadoras e progressistas do urbanista Prestes Maia. Calcadas no ideário moderno do arranha céu e da abertura de largas avenidas, a expansão urbana e o uso do automóvel foram incentivados. Devido à sua localização privilegiada em relação à capital do Estado de São 
Paulo, Campinas teve sua economia beneficiada pelo processo de informatização do território, o qual envolve a ampliação e diversificação das redes de transportes e comunicações propiciando uma maior conectividade entre diferentes localizações (SANTOS, 1991). Esse processo possibilitou a expansão e interiorização da indústria no Estado, sobretudo a partir da década de 1970. A dinamização da economia fez com que a cidade passasse a atrair um contingente cada vez maior de migrantes, originários tanto da Região Metropolitana de São Paulo quanto de outras áreas do Estado, com destaque para o oeste paulista. Foi bastante expressiva também a migração vinda de Minas Gerais e do Paraná, assim como de vários estados da região Nordeste (BAENINGER, 2001; CAMPINAS, 1991).

O estabelecimento dessa população na cidade ampliou o processo de expansão urbana, originando novas áreas de ocupação periférica. O Plano Preliminar de Desenvolvimento Integrado (PDDI), lançado no princípio da década de 1970, previa o deslocamento e a ocupação pelas classes de média e alta renda da região localizada ao norte do centro, área de elevado valor agrícola (CAMPINAS, 1991). No entanto, a área do município mais intensivamente ocupada a partir da década de 1970 foi a região Sudoeste, caracterizada pelo baixo potencial agrícola e, portanto, menor valor do solo urbano e onde também se encontra 0 estoque de terras das cooperativas habitacionais atuantes. Essas características somadas à proximidade com o Aeroporto de Viracopos, as Rodovias Anhanguera e Santos Dumont e o Distrito Industrial favoreceram a ocupação dessa região por população de baixa renda, absorvendo boa parte dos migrantes que chegavam à cidade. Esse processo ganhou novo impulso na década de 1980 devida à implantação, pelo poder público, de vários conjuntos habitacionais de interesse social na região Sudoeste (CUNHA; OLIVEIRA, 2001).

A verticalização em Campinas teve início na área central, com a construção de edifícios, impulsionada pelo Código de Obras de 1934 e pela implantação do Plano de Melhoramentos Urbanos de 1938. Após 1965, com a redução do alcance do Plano, a verticalização no centro passou a destinar-se mais às atividades terciárias e o adensamento residencial passou a ocorrer prioritariamente em outras áreas da cidade (DEZAN, 2007). Essa transferência da verticalização residencial ocorreu primeiramente nas regiões lindeiras ao centro, como por exemplo, o bairro do Cambuí, espraiando-se em razão do crescimento da malha urbana e da valorização fundiária, de modo a formar diversos espaços verticalizados permeados por vazios urbanos e conectados pelo sistema rodoviário. A multiplicação de empreendimentos habitacionais destinados às classes populares na região sudoeste e de condomínios luxuosos na região norte da cidade, são alguns dos indicativos deste processo. $O$ perfil de uso das edificações verticais aprovadas nesse período também mudou, passando da maioria destinada a escritórios ou uso misto para uso predominantemente residencial (FERNANDES, 2005).

Embora o centro campineiro seja ainda muito dinâmico é comum encontrar edificações ociosas ou subutilizadas. $O$ uso residencial no centro histórico não chega a $15 \%$ das edificações (CARTY, 2014), sendo mais intenso nos bairros vizinhos a ele. O aumento da vacância em edificações, não acompanhado pela perda de moradores, denota a concentração de população em pontos específicos do centro. A força do comércio popular, inclusive informal, mostra a importância das classes populares na dinamização do espaço central (PEDROSO, 2007).

Com o intuito de resgatar as qualidades perdidas com a transferência de diversas funções do centro para outros bairros da cidade, a área central tornou-se alvo de diversos projetos. As primeiras eram apenas intervenções pontuais, voltadas para a revitalização do patrimônio, 


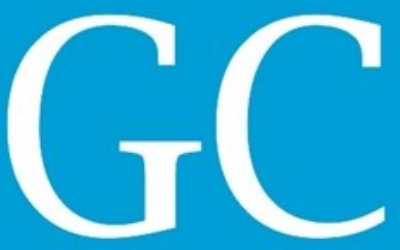

Revista Nacional de Gerenciamento de Cidades

porém, recentemente as propostas são mais complexas e propõem a re-funcionalização urbana a partir da valorização da fluidez do território, adotando a mobilidade urbana como foco de alguns desses projetos (OLIVEIRA, 2012). Recentemente, a região da Avenida Francisco Glicério, principal via da região central, passou por um processo de revitalização. Contudo, as intervenções públicas permanecem restritas ao plano espacial e ao sistema viário, não existindo nenhuma ação direta no que diz respeito à questão habitacional.

Atualmente, o planejamento urbano em Campinas se dá por macrozoneamento, delimitado conforme as características territoriais observadas, totalizando nove macrozonas. Estas, por sua vez, são divididas em 34 Áreas de Planejamento ( $A p^{\prime}$ 's), que são subdivididas em unidades menores chamadas Unidades Territoriais Básicas (UTB's). No centro da Macrozona 4 encontrase o perímetro reconhecido como área central e que é objeto deste estudo. Corresponde à Área de Planejamento 21 (Figura 1). Trata-se da porção mais centralizada e de melhor infraestrutura do município e compreende as UTB's: 30 - Guanabara, 31 - Cambuí, 34 - Centro e 35 - Bosque (CAMPINAS, 2006).

Figura 1: Mapa de Campinas com os limites das Áreas de Planejamento - destaque para Ap 21 (região central).

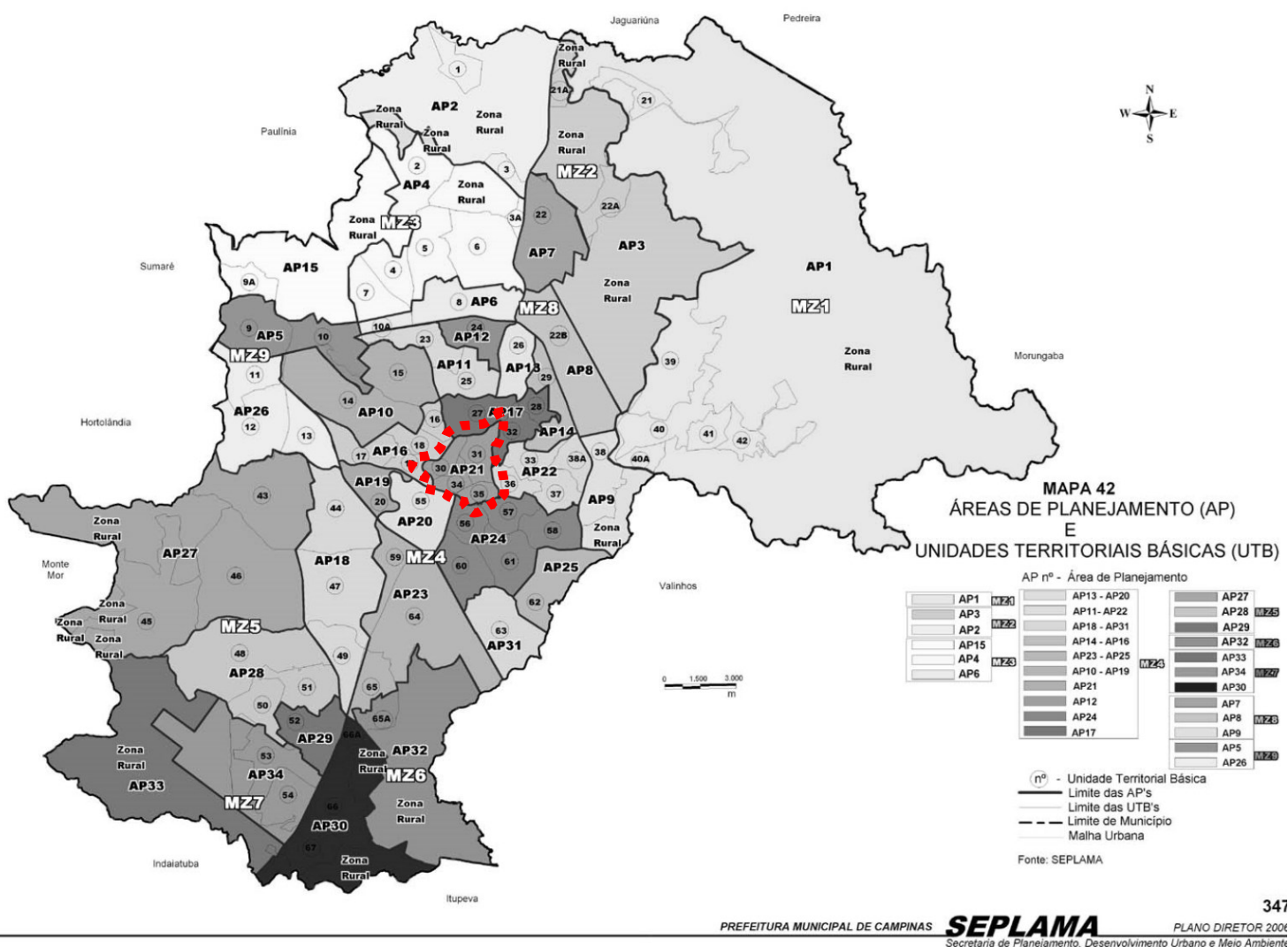

Fonte: Secretaria de Planejamento e Desenvolvimento Urbano de Campinas, Plano Diretor de 2006 - Anexo 3 Modificado pelas autoras. 
O processo de expansão urbana provocou alterações demográficas na região central da cidade (Tabela 1). Essa área experimentou ondas sucessivas de redução e ganho no número absoluto de moradores, sobretudo a mutação do perfil socioeconômico da população residente ao longo das décadas. A perda de população na região central entre 1970 e 1980 parece estar relacionada à migração da população moradora para as novas áreas urbanas estabelecidas nas periferias. A instituição da Lei 6766/79, que regulamentou a abertura de novos loteamentos aumentando as exigências de implantação de infraestrutura por parte dos loteadores, pode ter favorecido o incremento de população na área entre 1980 e 1991. No período de 1991 a 2000 houve novamente redução no contingente populacional, tendência que seria revertida entre 2000 e 2010, provavelmente devido a fatores como a instituição de planos e políticas para revitalização do espaço central e flexibilização na legislação para implantação de novos empreendimentos de habitação coletiva (OLIVEIRA, 2012).

Tabela 1 - Evolução da População Residente, segundo os Censos Demográficos IBGE.

\begin{tabular}{lccccccccc}
\hline Região & $\begin{array}{c}\text { População } \\
\mathbf{1 9 7 0}\end{array}$ & $\begin{array}{c}\text { População } \\
\mathbf{1 9 8 0}\end{array}$ & $\begin{array}{c}\text { Taxa } \\
\text { Cresc. } \\
\mathbf{7 0 / 8 0}\end{array}$ & $\begin{array}{c}\text { População } \\
\mathbf{1 9 9 1}\end{array}$ & $\begin{array}{c}\text { Taxa } \\
\text { Cresc. } \\
\mathbf{8 0 / 9 1}\end{array}$ & $\begin{array}{c}\text { População } \\
\mathbf{2 0 0 0}\end{array}$ & $\begin{array}{c}\text { Taxa } \\
\text { Cresc. } \\
\mathbf{9 1 / 2 0 0 0}\end{array}$ & $\begin{array}{c}\text { População } \\
\mathbf{2 0 1 0}\end{array}$ & $\begin{array}{c}\text { Taxa } \\
\text { Cresc. } \\
\mathbf{2 0 0 0 / 2 0 1 0}\end{array}$ \\
\hline UTB 30 & 11.215 & 9.441 & $-1,71$ & 11.560 & 1,88 & 10.193 & $-1,39$ & 12.413 & 1,99 \\
UTB 31 & 20.562 & 19.961 & $-0,3$ & 26.168 & 2,49 & 24.895 & $-0,55$ & 24.696 & $-0,08$ \\
UTB 34 & 19.010 & 15.996 & $-1,71$ & 16.626 & 0,35 & 13.458 & $-2,32$ & 15.782 & 1,61 \\
UTB 35 & 12.043 & 13.903 & 1,45 & 14.645 & 0,47 & 14.569 & $-0,06$ & 14.535 & $-0,02$ \\
Reg. Central & 62.830 & 59.301 & $-0,58$ & 68.999 & 1,53 & 63.115 & $-0,89$ & 67.426 & 0,66 \\
Campinas & 375.864 & 664.559 & 5,86 & 847.595 & 2,24 & 969.396 & 1,5 & 1.080 .113 & 1,09 \\
\hline
\end{tabular}

Fonte: Elaboração das autoras com base nas tabulações realizadas pela Seplama Campinas dos Censos demográficos de 1970 a 2010.

O levantamento realizado junto ao Departamento de Uso e Ocupação do Solo da Prefeitura Municipal indicou 53 projetos de habitação coletiva aprovados na região central de Campinas, entre os anos de 2000 e 2015. Esse levantamento mostrou uma aprovação expressiva de projetos dessa natureza, na forma de edifícios de apartamentos bastante verticalizados, concentrados principalmente a norte e nordeste da Avenida Francisco Glicério (Figura 2), ou seja, a área com melhor infraestrutura da região central. Apenas 7,5\% dos empreendimentos localizam-se fora dessa área. A aprovação de empreendimentos é também diferenciada de acordo com a UTB, sendo muito mais frequente nas regiões dos bairros Cambuí e Guanabara.

Dentre os empreendimentos identificados, a grande maioria envolve a anexação de lotes e demolição de antigas edificações, como casas e sobrados, indicando mudanças de uso do solo urbano relacionadas ao enobrecimento. Importante destacar que a re-funcionalização do centro histórico de Campinas aparece na década de 2000 como questão prioritária do poder público municipal, através do Plano de Requalificação da Área Central de Campinas e posteriormente do Projeto Centro. Essas propostas foram marcadas pelo forte apelo à afirmação do consumo cultural no centro, cuja re-funcionalização estaria articulada a uma estratégia maior de construção de uma imagem positiva da cidade e sua inserção nos circuitos globais da economia. Assim, a gestão da cidade naquela época investiu em empreendimentos 
como a construção da nova rodoviária e do terminal metropolitano na área do complexo ferroviário na área central, com planos de futuramente abrigar a estação do TAV entre Campinas, São Paulo e Rio de Janeiro. Entretanto, a problemática habitacional não foi contemplada pela gestão do município, mesmo que este conviva com um elevado déficit habitacional.

Figura 2 - Localização dos empreendimentos de Habitação Coletiva Aprovados pela Prefeitura Municipal de Campinas entre os anos de 2000 e 2015.

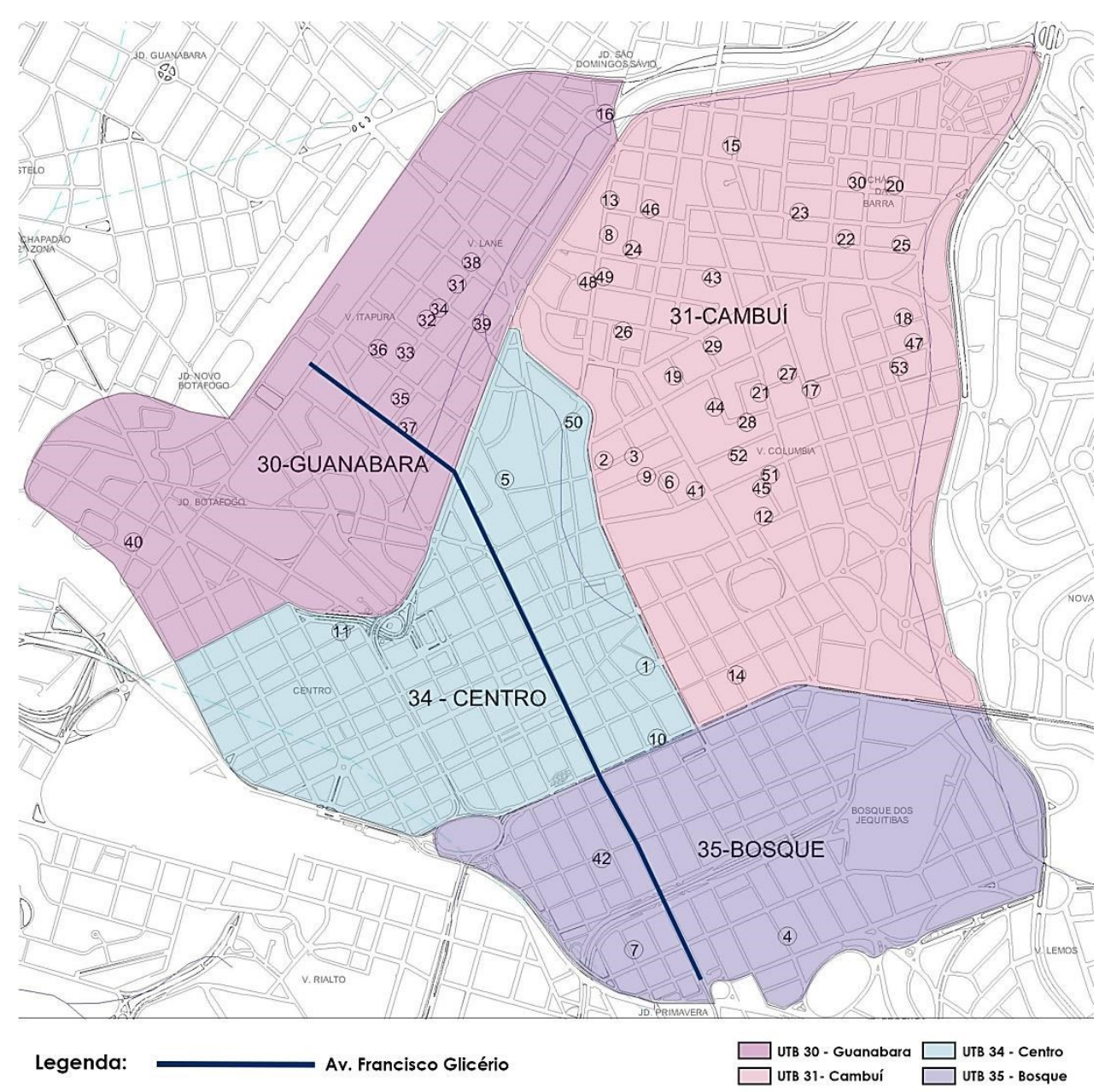

Fonte: Mapeamento realizado pelas autoras, a partir dos dados da Prefeitura de Campinas

Do total de projetos aprovados, houve acesso permitido para 43 projetos $(81,13 \%)$, sendo que alguns se encontravam em análise no setor jurídico e outros no gabinete do prefeito, sem previsão de liberação. A grande parte dos empreendimentos consultados foi aprovada ou concluída entre 2011 e 2015 (72\%), o que demonstra o aquecimento do mercado naquele período (Tabela 2). 
Tabela 2 - Número de empreendimentos de habitação coletiva aprovados pela Prefeitura de Campinas entre 2000 e 2015, por períodos.

\begin{tabular}{|l|l|l|l|l|l|l|}
\hline \multirow{2}{*}{$\begin{array}{c}\text { UTB/ } \\
\text { Período }\end{array}$} & \multicolumn{2}{|c|}{$2005-2010$} & \multicolumn{2}{c|}{$2011-2015$} & \multicolumn{2}{c|}{ Total } \\
\cline { 2 - 7 } & Aprov. & Concl. & Aprov. & Concl. & Aprov. & Concl. \\
\hline 30 & 1 & 5 & 2 & 4 & 3 & 9 \\
\hline 31 & & 6 & 5 & 14 & 5 & 20 \\
\hline 34 & & & 2 & 2 & 2 & 2 \\
\hline 35 & & & 1 & 1 & 1 & 1 \\
\hline AP 21 & 1 & 11 & 10 & 21 & 11 & 32 \\
\hline
\end{tabular}

Fonte: Tabulação realizada pelas autoras a partir dos dados fornecidos pela Prefeitura de Campinas, relativos a 43 processos completos.

Considerando as mudanças no perfil socioeconômico da população entre os anos de 2000 e 2010 (Tabela 3) constata-se, como é comum ocorrer na região central de outras grandes cidades, um processo de popularização. Tal processo caracteriza-se pelo empobrecimento da população residente e pela substituição do comércio e serviços tradicionalmente oferecidos no centro por outros destinados às classes populares, apresenta também aumento das atividades econômicas informais, tendência que já vinha se delineando em décadas anteriores (Pedroso, 2007).

Tabela 3 - Percentual dos Responsáveis pelos domicílios segundo faixas de rendimento (salários mínimos)

\section{Censos de 2000 e 2010}

\begin{tabular}{|c|c|c|c|c|c|c|c|c|c|c|c|c|c|c|c|c|}
\hline \multirow[t]{2}{*}{ Região } & \multicolumn{2}{|c|}{\begin{tabular}{|c|} 
Total de \\
Responsáveis
\end{tabular}} & \multicolumn{2}{|c|}{ Até $1 / 2 \mathrm{~s} . \mathrm{m}$} & \multicolumn{2}{|c|}{$1 / 2$ a 3 s.m } & \multicolumn{2}{|c|}{3 a 5 s.m } & \multicolumn{2}{|c|}{5 a 10 s.m } & \multicolumn{2}{|c|}{10 a 20 s.m } & \multicolumn{2}{|c|}{$\begin{array}{c}\text { Mais de } 20 \\
\text { s.m }\end{array}$} & \multicolumn{2}{|c|}{ Sem renda } \\
\hline & 2000 & 2010 & 2000 & 2010 & 2000 & 2010 & 2000 & 2010 & 2000 & 2010 & 2000 & 2010 & 2000 & 2010 & 2000 & 2010 \\
\hline 30-Guanabara & 4.617 & 6.241 & 0,04 & 0,40 & 7,69 & 27,81 & 11,33 & 21,07 & 28,22 & 26,72 & 27,07 & 12,33 & 20,97 & 3,28 & 4,72 & 8,36 \\
\hline $31-C$ & 9.950 & 11.496 & 0,04 & 0,24 & 4,59 & 13,40 & ,73 & 13,54 & 18,22 & 26,65 & 26,57 & 23,76 & 42,50 & 14,27 & 2,36 & 8,15 \\
\hline 34-Centro & 6.163 & 7.828 & 0,03 & 0,32 & 11,78 & 35,55 & 15,27 & 21,35 & 32,5 & 21,56 & 23,14 & 8,67 & 14,72 & 2,66 & 2,53 & 9,89 \\
\hline 35-Bosque & 6.431 & 6.945 & 0,03 & 0,32 & 9,70 & 28,63 & 10,31 & 19,74 & 27,04 & 27,56 & 28,35 & 11,58 & 21,88 & 2,78 & 2,72 & 9,39 \\
\hline AP 21 & 27.161 & 32.510 & 0,035 & 0,30 & 7,98 & 24,76 & 9,93 & 18,19 & 25,25 & 25,54 & 26,29 & 15,33 & 27,65 & 6,90 & 2,88 & 8,87 \\
\hline
\end{tabular}

Fonte: Elaboração das autoras com base nas tabulações realizadas pela Seplama Campinas, dos Censos

demográficos de 2000 e 2010.

No que diz respeito a faixa de renda dos responsáveis pelo domicílio, é possível perceber (Figura 3) que, apesar da popularização socioeconômica, a região central da cidade ainda concentra população de renda média e alta, assim como as regiões Norte e Leste, o que fica evidente na comparação com outras regiões do município. Isso denota também a persistência da concentração tanto de recursos públicos quanto de investimentos privados no espaço urbano. 


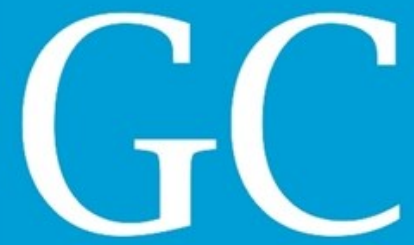

Revista Nacional de

Gerenciamento de Cidades

National Journal of Cities Management

Figura 3 - Percentual de responsáveis pelo domicílio com rendimento mensal acima de 20 salários mínimos (Divisão por UTB's) - Censo 2000

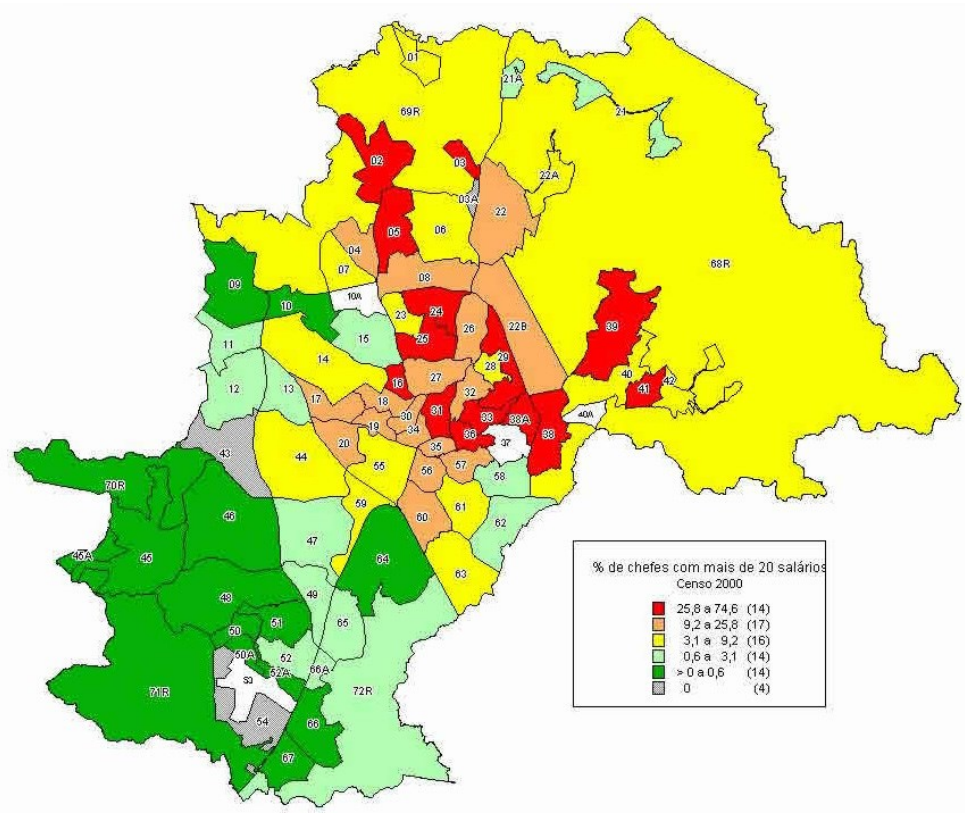

Fonte: Prefeitura Municipal de Campinas - Deplan/Seplama

A densidade populacional, de uma maneira geral, também permanece alta quando comparada ao restante da cidade (Figura 4 e Tabela 3). Sendo as UTB's 34-Centro e 35-Bosque as mais densas do município.

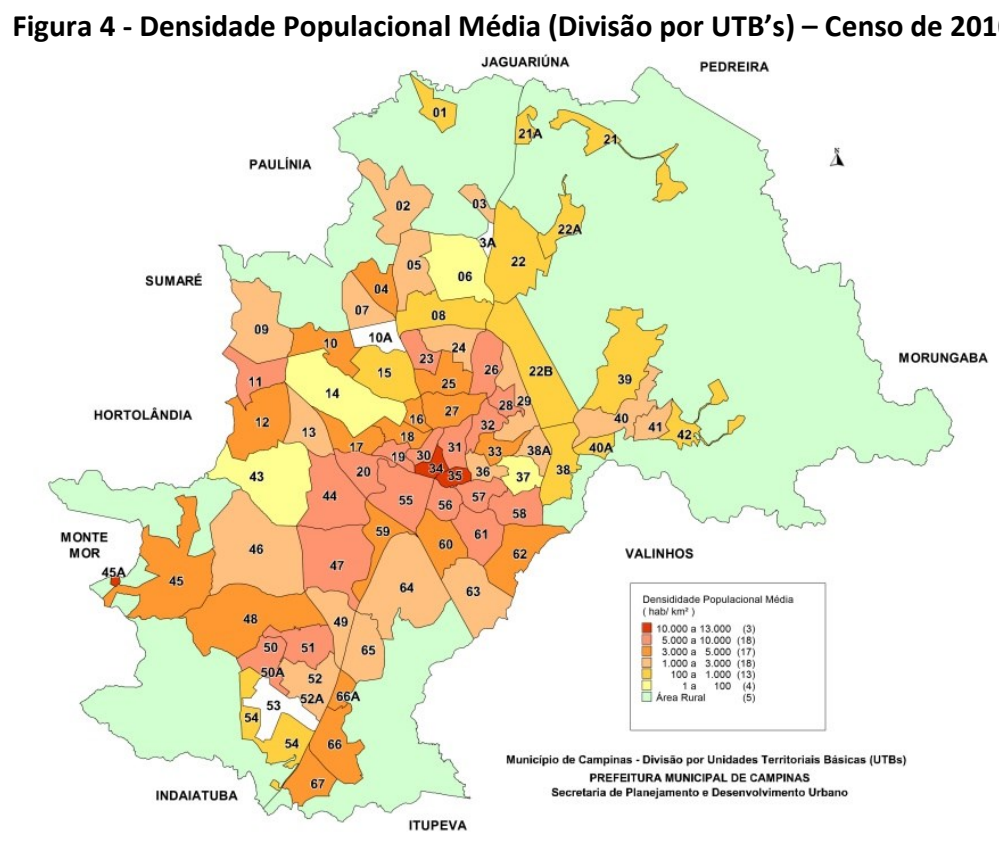

Fonte: Prefeitura Municipal de Campinas - Deplan/Seplama 
A região central apresenta ainda um percentual elevado de idosos (Figura 5) na composição de sua população em relação às outras áreas da cidade, assim como redução na participação da população infantil e adolescente (Tabela 4). Esse cenário reitera a tendência nacional de redução da taxa de fecundidade e envelhecimento da população (RODRIGUES; BAENINGER, 2010), podendo também apontar a busca de melhor qualidade de vida, por parte dos idosos, proporcionada pela localização mais central e próxima dos equipamentos e serviços urbanos. É considerável também o aumento da população jovem (de 20 a 29 anos).

Figura 5 - Percentual da população residente com 70 anos ou mais no município de Campinas (divisão por UTB's) - Censo de 2000

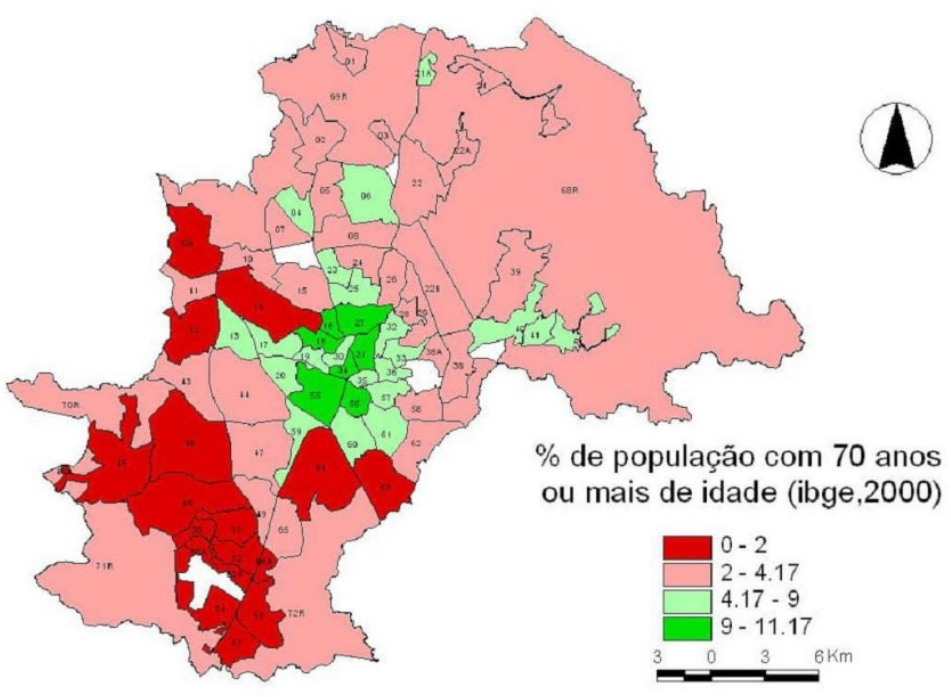

Fonte: Prefeitura Municipal de Campinas - Deplan/Seplama

Tabela 4 - População por Grupos de Idade - Comparação entre os Censos de 2000 e 2010

\begin{tabular}{|c|c|c|c|c|c|c|c|c|c|c|c|c|c|c|c|c|}
\hline \multirow[b]{2}{*}{ Região } & \multicolumn{2}{|c|}{0 a 9 anos } & \multicolumn{2}{|c|}{10 a 19 anos } & \multicolumn{2}{|c|}{20 a 29 anos } & \multicolumn{2}{|c|}{30 a 39 anos } & \multicolumn{2}{|c|}{40 a 49 anos } & \multicolumn{2}{|c|}{50 a 59 anos } & \multicolumn{2}{|c|}{60 a 69 anos } & \multicolumn{2}{|c|}{70 anos ou +} \\
\hline & 2000 & 2010 & 2000 & 2010 & 2000 & 2010 & 2000 & 2010 & 2000 & 2010 & 2000 & 2010 & 2000 & 2010 & 2000 & 2010 \\
\hline 30-Guanabara & 799 & 75 & 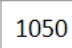 & 951 & 2487 & 317 & 1 & 92 & 31 & 786 & 26 & 42 & 00 & 861 & 12 & 73 \\
\hline $31-c$ & 1921 & 1524 & 3155 & 1916 & 4464 & 4478 & 3968 & 4057 & 4005 & 3379 & 2833 & 3780 & 2021 & 2553 & 2528 & 3100 \\
\hline 34-Ce & 017 & 846 & 1407 & 1416 & 3073 & 3759 & 2352 & 2744 & 1906 & 2213 & 1204 & 2003 & 1074 & 1315 & 1434 & 1904 \\
\hline $35-B$ & 1275 & 911 & 1628 & 1176 & 2817 & 3048 & 2841 & 2587 & 2345 & 2137 & 1310 & 2074 & 1072 & 1216 & 1275 & 1459 \\
\hline AP 21 & 5012 & 4040 & 7240 & 5459 & 12841 & 14602 & 11132 & 11980 & 9687 & 9515 & 6173 & 9299 & 4767 & 5945 & 6049 & 7336 \\
\hline
\end{tabular}

Elaboração das autoras com base nas tabulações realizadas pela Seplama Campinas, dos Censos demográficos de 2000 e 2010. 


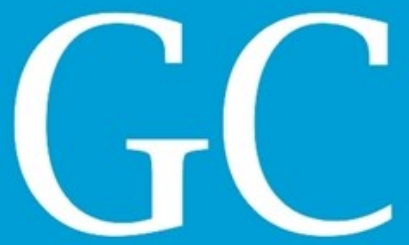

Revista Nacional de Gerenciamento de Cidades

O tamanho das famílias na região central é diferenciado em relação ao município de Campinas como um todo. Os bairros centrais caracterizam-se pela presença de famílias menores, seguindo a tendência à individualização cada vez maior dos modos de vida na contemporaneidade. Ocorre também a redução progressiva do número de habitantes por domicílio, tanto na região central quanto no município de Campinas ao longo do tempo (Tabela 5).

Tabela 5 - Média de Moradores por domicílio particular permanente

\begin{tabular}{|l|l|l|}
\hline Região & Censo 2000 & Censo 2010 \\
\hline 30-Guanabara & 2,17 & 2,00 \\
\hline 31-Cambuí & 2,50 & 2,16 \\
\hline 34-Centro & 2,18 & 2,02 \\
\hline 35-Bosque & 2,27 & 2,09 \\
\hline AP 21-Região Central & 2,31 & 2,08 \\
\hline Campinas & 3,38 & 3,08 \\
\hline
\end{tabular}

Fonte: Elaboração das autoras com base nas tabulações realizadas pela Seplama Campinas, dos Censos demográficos de 2000 e 2010.

Com relação ao grau de instrução dos responsáveis pelo domicílio é possível constatar o baixo percentual de população não alfabetizada na região central (Figura 6). No ano de 2000, enquanto a parcela não alfabetizada da população no município superava $15 \%$, nos bairros centrais ela não chegava a $3 \%$, indicando maior qualificação da população moradora da área central.

Figura 6 - Percentual de responsáveis pelo domicílio não alfabetizados no município de Campinas (divisão por UTB's) - Censo de 2000

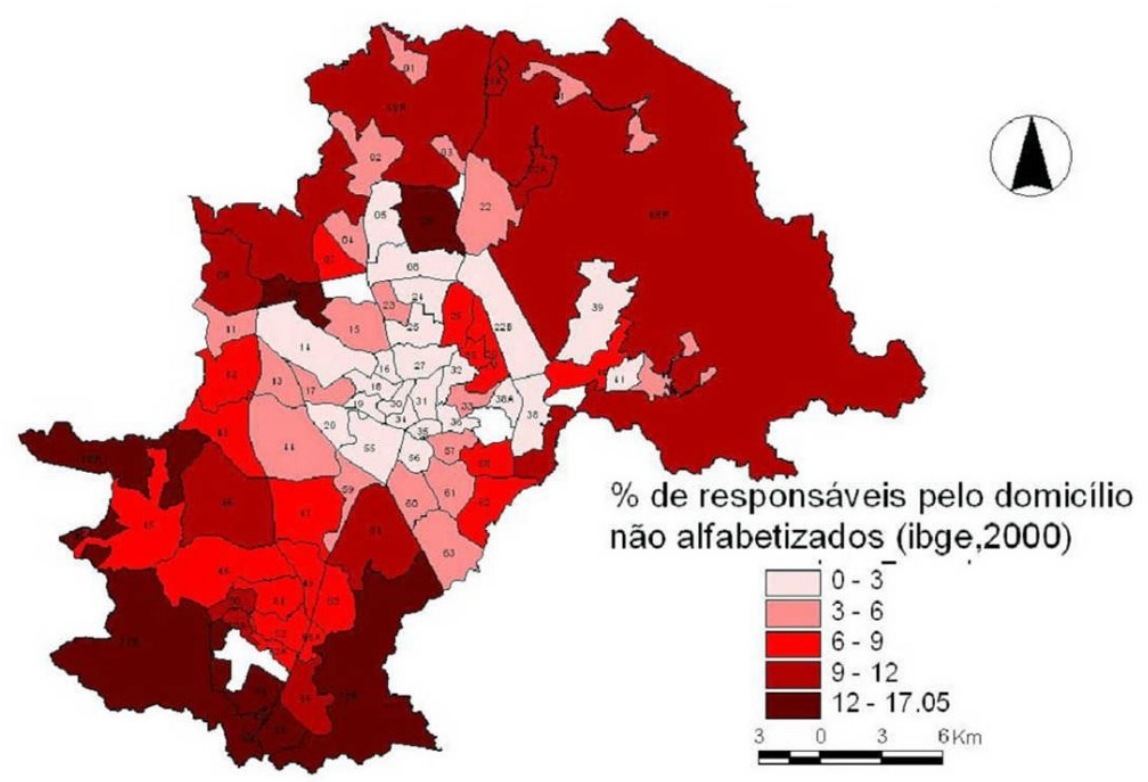

Fonte: Prefeitura Municipal de Campinas - Deplan/Seplama 


\section{CONCLUSÃO}

A recente e acentuada verticalização da moradia na região central de Campinas confirma a valorização do solo urbano ainda muito elevada, de modo que para o mercado, interessa a maximização do retorno do empreendimento, por meio da construção de condomínios verticais de alto padrão. A atuação da gestão pública no período, seja pelos empreendimentos, seja pela legislação urbanística adotada, reforçou tal valorização, uma vez que seus investimentos também se concentraram na região.

As características das unidades habitacionais, contudo, expressam aos diferentes valores do solo urbano, ainda que na mesma região. Enquanto no Centro e na região do Bosque predominam as tipologias de 1 e 2 dormitórios, no bairro Guanabara predominam as tipologias com mais de 3 dormitórios e com 4 ou 5 banheiros. Já no bairro Cambuí, onde o custo da terra é bastante elevado, percebe-se um misto entre essas tipologias, sendo as menores provavelmente destinadas a jovens profissionais ou ainda a idosos, que representam uma significativa parcela da população na área. Essa é também a UTB que concentra maior número de empreendimentos.

Os dados censitários a partir dos anos 1970 apontam constantes mudanças na área central, alternando períodos de perda ou ganho no número absoluto de moradores, sem, contudo, apresentar um processo de despovoamento significativo em nenhuma das décadas consideradas. A análise combinada da produção recente de habitação coletiva e dos dados censitários de 2000 e 2010 permite concluir que o não esvaziamento populacional na Região Central de Campinas se dá por uma transferência demográfica contínua de população, a qual está aos poucos alterando a configuração sócio territorial da região central da cidade. A oferta de unidades habitacionais de características distintas remete não à uma diversidade social maior, mas sim às mudanças nos modos de vida contemporâneos e nas novas conformações dos núcleos familiares, o que demanda programas habitacionais diferentes daqueles destinados às famílias de baixa renda. Dessa forma, mesmo as unidades habitacionais aparentemente mais modestas possuem valor de mercado inacessível para as classes de mais baixa renda, reforçando uma tendência cada vez mais seletiva.

Os dados demográficos censitários apontam para uma popularização do centro entre 2000 e 2010. No entanto, com a transformação dos bairros centrais e a crescente construção de empreendimentos nos últimos cinco anos, detecta-se possível tendência de substituição da população moradora por outra de maior poder aquisitivo e de mudanças também nas características dos empreendimentos apontando para um cenário de enobrecimento social, sucedendo um período marcado pela popularização, o que revela um espaço em plena mutação. O protagonismo do mercado imobiliário nesse processo é evidente e, infelizmente, ainda com apoio do poder público municipal através de leis urbanísticas e obras de revitalização no centro.

\section{AGRADECIMENTO}

À CAPES, pelo apoio. 


\section{REFERÊNCIAS BIBLIOGRÁFICAS}

BAENINGER, Rosana (org.). População e Cidades: subsídios para o planejamento e para as políticas sociais. Campinas: Núcleo de estudos de População - Nepo/Unicamp; Brasília: UNFPA, 2010. 304 p.

BAENINGER, Rosana. Região Metropolitana de Campinas: expansão e consolidação do urbano paulista. In: HOGAN, Daniel J.; BAENINGER, Rosana; CUNHA, José M. P. da; CARMO, Roberto L. do (orgs.) Migração e ambiente nas aglomerações urbanas. Campinas: NEPO/UNICAMP, 2001. p.321-348.

BIDOU-ZACHARIASEN, Catherine (coord). De volta à cidade: dos processos de gentrificação às políticas de "revitalização" dos centros urbanos. São Paulo: Annablume, 2006. Trad. de Helena Menna Barreto Silva.

CAMPINAS. Lei Complementar no 15, de 27 de Dezembro de 2006. Dispõe sobre o Plano Diretor do município de Campinas. Diário Oficial do Município de Campinas, Campinas, n. 9.074, Ano XXXVI, 29 dez. 2006. p. 3-12. Disponível em: <http://www.campinas.sp.gov.br/uploads/pdf/1218212036.pdf> Acesso em: 26 Ago. 2014.

CAMPINAS, Secretaria Municipal de Habitação. Plano Municipal de Habitação. Campinas, 2011.

CAMPINAS. Campinas: Subsídios para a discussão do Plano Diretor. Campinas, 1991.

CARTY, Carolina Gabriel. Vacância no centro de Campinas e o planejamento urbano brasileiro, 19902014. 2014. 208p. Dissertação (mestrado) - Centro de Ciências Exatas, Ambientais e de Tecnologias, Pontifícia Universidade Católica de Campinas, Campinas.

CUNHA, José M. P.; OLIVEIRA, Antonio A. B. População e Espaço Intra-urbano em Campinas. In: HOGAN, Daniel J.; BAENINGER, Rosana; CUNHA, José M. P. da; CARMO, Roberto L. do (orgs.) Migração e ambiente nas aglomerações urbanas. Campinas: NEPO/UNICAMP, 2001. p.350-393.

DEZAN, Waldir V. A implantação de uma modernidade: o processo de verticalização da área central de Campinas. 2007. 190 p. Diss (mestrado) - Faculdade de Engenharia Civil, Arquitetura e Urbanismo, Universidade Estadual de Campinas, Campinas.

FERNANDES, T. F. A habitação verticalizada em Campinas-SP: a evolução dos programas arquitetônicos. 2005. 98p. Dissertação (mestrado) - Faculdade de Engenharia Civil, Arquitetura e Urbanismo, Universidade Estadual de Campinas, Campinas.

HARVEY, David. A produção capitalista do espaço. 2ạ ed. São Paulo: Annablume, 2006. 252p.

HOGAN, Daniel J.; BAENINGER, Rosana; CUNHA, José M. P. da; CARMO, Roberto L. do (orgs.) Migração e ambiente nas aglomerações urbanas. Campinas: NEPO/UNICAMP, 2001. p.350-393.

OLIVEIRA, M.R.S. Intervenções Urbanas e Representações do Centro da Cidade de Campinas/SP: Convergências e Divergências. Tese (Doutorado) Instituto de Geociências Universidade Estadual de Campinas, 2012.

PEDROSO, Francis. O centro de Campinas (SP) - usos e transformações. 2007.122p. Dissertação (mestrado) - Instituto de Geociências, Universidade Estadual de Campinas, Campinas.

RODRIGUES, Fabíola; BAENINGER, Rosana. Dinâmica da população e políticas sociais. In: BAENINGER, Rosana (org.). População e Cidades: subsídios para o planejamento e para as políticas sociais. Campinas: Núcleo de estudos de População - Nepo/Unicamp; Brasília: UNFPA, 2010. p. 25-33.

SOMEKH. A cidade vertical e o urbanismo modernizador: São Paulo 1920-1929. São Paulo: Studio Nobel: Editora da Universidade de São Paulo: FAPESP, 1997. 173p. 
Revista Nacional de

Gerenciamento de Cidades

National Journal of Cities Manasement

MILTON SANTOS. Meio Técnico cientifico e urbanização. Revista Resgate (Centro de Memória da UNICAMP), Campinas, n.3, 1991.

SMITH, Neil. A gentrificação generalizada: de uma anomalia local à "regeneração" urbana como estratégia urbana global. In: BIDOU-ZACHARIASEN, Catherine (coordenadora). De volta à cidade: dos processos de gentrificação às políticas de "revitalização" dos centros urbanos. São Paulo: Annablume, 2006. Tradução de Helena Menna Barreto Silva.

VILLAÇA, Flávio. Espaço intra-urbano no Brasil. São Paulo: Studio Nobel, 1998. 373p.

VILLAÇA, Flávio. Reflexões sobre as cidades brasileiras. São Paulo: Studio Nobel, 2012. 295p. 